In A Tashakorri and C Teddlie (eds) The Handbook of Mixed Methods Research, Sage 2010

\title{
The Use of Mixed Methods in Biographical Research
}

(C) Ann Nilsen and Julia Brannen

26 May 2009

The study of social change has been a core concern of the social sciences. In particular sociology has its origins in understanding a changing world, a concern that dates back to the classical studies of the late $19^{\text {th }}$ and the early $20^{\text {th }}$ century. Of all the different types of data generated that locates the individual in relation to the dimensions of both time and space, biographical data are the most 'qualitative'. Kohli (1981) defines a biographical account, or life story, as ' $[. .$.$] the mode by which the individual represents those aspects of his past which$ are relevant to the present situation, i.e. relevant in terms of the (future-oriented) intentions by which he guides his present actions' (p.65). ${ }^{1}$

Biographical research requires both intensive and extensive lenses with which to produce knowledge about human lives as they develop over historical time and the life course. Its methods require understanding and interpretation of human experience across time and space while elucidating individual action and engagement in society. Biographical data add an additional layer of complexity to the study of society. Biographical researchers work with a variety of different types of data including documents such as written autobiographies, letters and diaries (Thomas and Znaniecki [1918-20] 1958), interviews, surveys, secondary data (statistical trends, historical accounts) (Bertaux 1981; Bertaux and Kohli 1984; Bertaux and Thompson 1997); and increasingly websites, weblogs and videos (Plummer 2001; Bornat 2008).

In the chapter, we will discuss the different developments that have taken place in biographical research from the 1920s to the present and the ways in which the approach has engaged, either explicitly or implicitly, with what can be described as qualitative and quantitative data. For, although the language of mixing methods is fairly recent, current debates around mixed methods research have resonances with debates in biographical research that were common in both earlier and current periods. In the chapter, we will make reference to some of these debates and illustrate them with exemplar studies and discuss their use of different types of data and methods and their consequences for the framing of the analyses in the publications that were generated from them. We begin by providing an overview of the origins of biographical research and then go on to the ways qualitative and quantitative approaches were combined in biographical research over the course of the $20^{\text {th }}$ century until the present day. As we will demonstrate, early biographical studies inspired a focus on individual lives as they develop over historical time and the life course, not only in sociological studies but in related fields such as psychology, social anthropology and history. The discussion in this chapter is however confined to sociology.

In many instances biographical material has been combined with other sources of data. However, whether supplementary sources of information were actually referred to as 'data' by

\footnotetext{
${ }^{1}$ Since we are sociologists the focus of the chapter is primarily from this perspective. Bertaux (1981), another sociologist, includes two types of biographical accounts: a 'life story' told by a person in an interview about his or her own life and a 'life history' which is both the person's story but with additional data based upon records and accounts of other informants. (Bertaux 1981, pp. 7-9).
} 
the researchers and were an explicit part of the analysis is another matter. We will argue that this needs to be understood in the relation to the historical context in which the research was carried out. In this sense biographical methods should be of interest to those involved in mixed methods research methodology. As in all mixed methods studies (see especially chapters $\mathrm{X}$ and $\mathrm{Y}$ in this Handbook), so in biographical research there are different ways of linking data sources. As we will demonstrate, it is not only the definition of the research question that decides how methods are chosen and data are linked but also the way that social phenomena are conceptualised, the methodological assumptions that are made, and the debates which underpin a study or set of studies at a given historical period, that is assumptions about ontology and epistemology.

\section{The biographical approach: The Polish Peasant in Europe and America}

The start of the biographical method is attributed to the work of William I. Thomas and Florian Znaniecki and their study published in The Polish Peasant in Europe and America. This is considered to be the first biographical study in sociology and it inspired researchers not only in sociology but in all other social science disciplines over the $20^{\text {th }}$ century. The work was published between 1918 and 1920 in five volumes, and republished in 1958 in a two volume edition, with some changes made to the order of parts and different pagination. Volumes I and II in the original edition concern the peasant primary groups in Poland and their experiences of the rapid industrialisation at home and rising rates of migration to America and Germany. Volume III is an autobiography of an immigrant of peasant origin (Wladek). Volume IV is about the development and reorganisation of peasant communities in Poland under the new regimes of agriculture and modernisation, and Volume $\mathrm{V}$ explores the situation of Polish immigrants in the Chicago area, and the disorganisation of communities in their new surroundings. There is also a long Methodological Note in the original Volume I, that Thomas explained later was written after the study had been completed (Blumer 1979, p. 83).

Thomas met Znaniecki on a field trip to Poland in 1913. Znaniecki then emigrated to the USA after World War I broke out. Together they collected an impressive amount of data of various kinds in their study of polish migrants. In Poland they collected newspaper articles, personal letters, archive material and personal stories. It was the first time that personal documents and biographies in particular had been used as data in an extensive sociological study.

The setting and timing of the development of the biographical approach in these studies are highly significant. At the time Chicago was the fastest growing North-American city and, with a huge immigrant population, the city had more than its share of social problems. Social work and sociology in the University ${ }^{2}$ were not then separate disciplines, and the approaches that were common in sociology were also influential among social workers. Empirical sociology in the Chicago department was inspired by Pragmatist philosophy (the writings of Peirce, James, Mead and Dewey). Many of the sociologists in the department saw their purpose as uncovering the conditions of hardship and identifying the causes for the human misery they witnessed in some Chicago communities. Indeed, empirical sociology was flourishing in the Chicago department at a time when in many other universities sociologists had not moved out of their armchairs. During this period many Chicago sociologists collected biographies or 'cases' as research material. In this context the term 'case' was borrowed from

\footnotetext{
${ }^{2}$ University of Chicago was the first to establish a department of Sociology, Albion Small in 1892, and establish a journal of sociology, The American Journal of Sociology 1895
} 
social work; social workers described writing up their clients' life stories as cases (Platt 1996). The life story approach hence became an important influence in empirical sociology.

W.I Thomas was a contemporary of another sociologist, Jane Addams ${ }^{3}$, whose work became influential in social work. She was the co-founder (with Ellen Gates Starr) of Hull House ${ }^{4}$ in Chicago, a charity established in 1889 , largely with the help of funding from an heiress, Helen Culver. Hull House was set up to educate and to alleviate the conditions of the poor communities in the city. Many employees of the Sociology Department, Mead, Thomas and Dewey in particular, were associated with the charity work of Hull House. Most were also politically active, particularly Thomas. This led to unfortunate consequences for his academic career. To make a long story short he was fired from his position at the University in 1918. By then the first two volumes of the Polish Peasant were published by the University of Chicago Press. However the University broke the contract for the remaining three volumes, which were published by a Boston publisher in 1920. Thomas never again obtained a tenured position. However his reputation was later restored among the American sociological community, in particular in the Appraisal Proceedings of the Polish Peasant conducted at the American Sociological Association in 1938.

\section{The 1938 Appraisal of The Polish Peasant}

In 1938 The American Sociological Association held a session where Herbert Blumer, ${ }^{5}$ an earlier student of Mead and also Thomas, gave an extensive review of The Polish Peasant where both Thomas and Znaniecki were present alongside a number of prominent sociologists. The methodological aspects of the work were a major focus of the debate which was produced verbatim in the published Appraisal Proceedings.

In making sense today of these methodological discussions, it is important to reflect on the historical time in which they took place. Hitler was in power in Germany. Scientists and social scientists were fleeing that country. They rejected the beliefs that underpinned the Third Reich as unscientific as well as unethical. Such a rejection reflected a commitment to a positivist stance on matters of methods and methodology which, in those circumstances, became a liberating and enlightening way of thinking.

The Polish Peasant study combined a variety of data, as mentioned previously, and the researchers' analysis of these was rigorous and thorough. Znaniecki (1934) would later publish a book on his pioneering method which he called analytic induction. ${ }^{6}$ Values and attitudes were key concepts in Thomas' and Znaniecki's analyses, where values were defined as 'the objective cultural elements of social life', and attitudes 'the subjective characteristics of the individual'. The researchers' aim was to uncover the 'social laws of becoming'. Although Thomas distanced himself from this ambition during the proceedings, it nevertheless demonstrates the research climate at that time; some thought social science should become a science alongside the natural sciences and therefore saw the uncovering of laws as important. One of Blumer's conclusions in his review of the work was they had not

\footnotetext{
${ }^{3}$ Jane Addams was rewarded the Nobel Peace Prize in 1931.

${ }^{4}$ Hull House grew in size and scope and became an important inspiration for similar charities across America. The founders were however inspired by Toynbee Hall (1885) in London.

${ }^{5}$ G.H. Mead defined his approach to sociological studies as 'social behaviourism' in contrast to Watson's 'behaviourism' which was a very influential school of thought in the early $20^{\text {th }}$ century. Blumer, although much inspired by Mead, did however not share his ontological and epistemological viewpoints (Lewis and Smith 1980).

${ }^{6}$ This method can be traced as one of the inspirations for Grounded Theory as formulated by Glaser and Strauss in their 1967 book (Platt 1996).
} 
been able to achieve their aim of identifying the 'social laws of becoming'. This led to a discussion about the relationship between the social and the natural sciences and whether the epistemological foundations of the social sciences should be different from those of the natural sciences.

During the Proceedings it became clear that the approach to methods and data adopted in The Polish Peasant represented challenges for sociology in general. Could subjective accounts be relied upon? What methods could be used to overcome subjective biases in the data? How could such data ever become 'representative'? By which means could a representative sample of life histories be achieved? How could researchers be sure that those who volunteered their life stories did not have their own agendas and interests? How could subjective accounts be thought to have value beyond the individual story? In grappling with such questions the panel touched upon a number of issues that still haunt what we now call 'qualitative research' and what was then referred to as 'naturalistic methods'.

Replying to challenges about the reliability of biographical, or 'subjective' material, W.I. Thomas said:

".. there is a collection of about 1000 Swedish case studies along the lines of criminology and psychology which are, on the whole, superior to anything I have seen. (...) In Sweden, all the cases in question are kept under observation and studies for a period of from two to six months. They write their stories themselves, but not extensively. They are interrogated at intervals and sometimes by different persons. The authorities communicate with the persons with whom the subjects have associated relatives, teachers, landlords, employers, neighbours, etc. The replies are very meticulous since the Swedish state can almost command in this respect. I conceive that this material has an all-round superiority to life histories alone' (Blumer 1979 [1939] p. 132.

Several points can be made about this quotation. One is the affinity drawn between life stories and case studies, and thus between social workers' involvement with 'delinquents', especially young people, and researchers studying these groups. In disciplines other than sociology such methods became more important over the years following the publication of The Polish Peasant. Another important point is that life histories and personal documents were not seen as sufficient material for sociological studies. In one sense what Thomas proposed here was indeed a mixing of methods! The third point that strikes us today is that the Swedish cases were all 'inmates' whose stories could be checked against a variety of sources, thus increasing their individual reliability. However, the respondents were not a volunteer sample but were 'command(ed)' to participate by the Swedish state. Studies of such large captive samples of 'cases' were later to become common in psychology and related disciplines, including in some early longitudinal studies as we shall later discuss.

\section{Empirical studies and methodological discussion in early post-war sociology}

In the inter-war period the main methodological discussions centred on debates about 'the case study method' and 'the statistical method', while in the post-war period statistical methods gained prominence at the expense of qualitative studies. Discussions focussed more and more on the technicalities of survey methods (Platt 1996).

During this period, Herbert Blumer was one of the most influential sociologists to engage in debates about methodology. Many of the viewpoints he expressed during the Appraisals 
Proceedings anticipated his later writings, where he argued against variable-driven research in the social sciences and made a case for a humanistic sociology based on sensitising rather than definitive concepts (see e.g. Blumer 1954).

However, Blumer was not the only voice to oppose mainstream sociological thought and practice at the time. Foremost amongst the critics of the contemporary trend was C.Wright Mills who received his $\mathrm{PhD}$ from the University of Wisconsin (1942) on the sociology of knowledge in American Pragmatism ${ }^{7}$ (Mills 1966). This body of thought influenced much of his writings in the sociology of knowledge (see for example 1939, 1940a and b). His ambition for sociology was formulated in an appendix to his most well known book, The Sociological Imagination (1981 [1959]). This book is one of the few texts from the period that set out to describe in great detail how empirical research should be carried out, while also giving good methodological reasons for the practices he recommended.

Although Mills himself did not carry out biographical studies as such, his influence on the field has been very important especially during the revival of biographical research in the 1970s, as we will discuss later. His vision for the discipline was to combine insights at both macro and micro levels of society, while also applying a processual approach to research questions; that social life must be studied and understood within particular historical periods. Thus he insisted that equal attention be paid to history and biography and that the sociological imagination, that is the power to formulate good research questions, should locate these at the intersection of biography and society. In so doing he proposed a programme for the conduct of sociological research which would fulfil the aim of generating knowledge to help people make sense of their lives. He thereby sought to take the discipline out of the grip of The Theory (structural functionalism as propounded by Talcott Parsons) on the one hand, and The Method (the statistical methods supported by Lazarsfeld and others) on the other (Mills [1954] 1963), both of which approaches had gained ground in Anglo-Saxon sociology in this period. In many social sciences, including sociology, large-scale surveys on the one hand, and controlled experiments on the other, were identified as the new ideal research designs since they could test hypotheses, which would in time lead to the accumulation of sophisticated bodies of theory, which were seen as essential to the ambition of arriving at social laws.

\section{Life course perspectives and longitudinal studies}

An important development within the quantitative tradition has been the longitudinal and cohort study in which the focus is on temporality and the individual life course of particular groups and cohorts. These studies have considerable narrative potential to provide highly detailed information about individuals (Elliott 2005) but, as we shall show, require interpretation in relation to historical context.

The affinity between a biographical approach and social work was noted earlier. Participants in longitudinal studies were often 'deviants', 'delinquents' and other groups of people who for some reason did not fit into the 'normal' fabric of society. An early exemplar was carried out by Eleanor and Sheldon Glueck $(1930)^{8}$, whose work was also remarked upon by Thomas in the Appraisal Proceedings. In 1940 the Gluecks began a second study of 500 delinquent and 500 non-delinquent white boys aged 14 (matched by age, ethnicity, type of neighbourhood and intelligence) and they followed them up at 25 and 32 (Glueck and Glueck 1943, 1950).

\footnotetext{
${ }^{7}$ The title of the thesis was A Sociological Account of Pragmatism: An Essay on the Sociology of Knowledge. It was edited by Horowitz and published posthumously in 1966.

${ }^{8}$ Glueck and Glueck 1930 Five Hundred Criminal Careers was based on a longitudinal study where a group of inmates were followed from 1911 to 1922, during imprisonment and five years after their release.
} 
As Laub and Sampson (1998) who worked on their archived data much later comment, the data were exceedingly rich; the Gluecks had collected data on a variety of dimensions of juvenile and adult development including major life course events. Their methods were various; interviews with the respondents and their families, but also with key informants (social workers, school teachers, employers, neighbours for example), and official records and criminal histories. This mixed method approach and the rigour of the investigation together with its longitudinal design set the study apart from criminological studies that preceded it. However, in the 1940s, the Gluecks had not aimed to integrate the richness and depth of their qualitative and quantitative data. From a methodological and epistemological viewpoint, the study was firmly grounded in a quantitative logic where issues of representativeness, generalisation and reliability were important, and the purpose was to arrive at causal explanations and the ability to predict. There was no attempt to treat the qualitative data in their own right.

\section{Cohort studies}

A particular form of longitudinal study is the cohort study which can be defined as 'an aggregate of individuals who experienced the same event within the same time interval' (Ryder 1965, p 845), the most common of which is the birth cohort. Again, the focus is on the individual and on temporality and a concern with social change. One of the most well known cohort studies is Glen Elder's Children of the Great Depression, first published in 1974, and republished in 1999 with an updated last chapter. Inspired by Karl Mannheim's 1928 essay, On the Problem of Generations, the purpose of the research was to study how historical context and economic deprivation shaped individuals' lives. The study is based upon similar types of material - both qualitative and quantitative - as the Gluecks' studies, but with one main difference: the cases were 'ordinary' children. The sample consisted of fifth graders (born around 1920) - 84 boys and 83 girls, all 167 white, from working- and middle class backgrounds living in Berkeley and Oakland, California. They were continuously studied over a seven year period from 1932 to 1939 and contacted again at five points in time until $1964 .{ }^{9}$

This is indeed an impressive study in terms of the depth and range of data. It stands out from other studies of its time because Elder explicitly stated that he chose to study effects of economic deprivation on theoretical and historical grounds, and not because he sought some de-contextualised predictive explanations about how deprivation in childhood would affect individuals over the life course in general (Elder 1999, p.6). Elder thus employed a life course sensitive frame for interpreting the data, as formulated by other earlier advocates of the cohort design (Ryder 1965). However, in contrast to e.g. Blumer's approach to sociology, Elder's approach was firmly grounded in a variable logic and in quantitative analysis. However, he did highlight the importance of social and historical context, a viewpoint he shared with those who came to revive the qualitative biographical approach in the same decade in which his groundbreaking study was published (see Bertaux 1981). Rather than making generalisations about how particular experiences of deprivation in childhood would affect individuals over

\footnotetext{
${ }^{9}$ Mothers were interviewed in 1932, 1934 and 1936; questionnaires were given to children in junior and senior high school (seven times in the period 1932-38), and staff in the schools were required to complete ratings of children's behaviour. Fathers were not interviewed. Children filled in questionnaires. Questions were mostly concerned with psychological topics such as attitudes, emotional climate in the home, parent-child relations etc. In 1941 and 1948 the sample was contacted again with questions about occupational activity. In 1953-54 the sample of children was interviewed and given physical and psychological assessments. A follow up in 1957-58 involved biographical interviews with focus on recollections of childhood and adolescence. The last major follow up was an extensive questionnaire in 1964. Of the whole sample 76 women and 69 men answered at least one of these follow ups.
} 
the life course irrespective of time and place, Elder concluded that effects of childhood deprivation related not only to the historical circumstances but to the points in the life course (age and cohort) in which they experienced it; the children in the Berkeley study were 8 years younger than children in the Oakland sample and it was these younger children whose lives were most disrupted by the depression.

In Children of the Great Depression discussions about methods are placed in an appendix, with detailed accounts about the types of data, methods of data collection and questions of reliability and validity. Elder relied on a great deal of information about other layers of context. One source of such data was the interviews carried out with the children's mothers. As the following quote indicates, he made use of these interviews but only for purposes of gaining insights of a general kind, and throughout the book, as illustrations.

These qualitative materials were found to be an invaluable source of insight and illustrations for the analysis, but they were not sufficiently systematic to permit codification. [...] The staff members who interviewed the mothers also rated them on personal characteristics, using a seven-point scale.' (Elder, 1999, p. 367).

The study also relies on information about the different historical periods through which the cohorts lived at various phases in the life course. It can therefore be argued that the interpretation of cohort studies does (and should) involve more than one type of data. Knowledge about the wider historical period is often derived from the literature, archived material and official statistics but these may only indirectly inform the analysis. More often than not, this contextual material is not presented by the researchers as sources of data, much less as mixed methods of analysis. Rather these data form an invisible aspect of the interpretative process or they are simply referred to as research literature. That this was the situation in the 1970s can be inferred from the following quote from Blumer:

"The jumbling together of naturalistic and nonnaturalistic methods of study has resulted, in my judgment, in a large amount of methodological confusion, a confusion that is more harmful because it is unrecognised" (Blumer, 1979 p. xxvii)

\section{The revival of the biographical method}

As indeed Bertaux (1981) has remarked, there was a sudden and radical 'collapse' in the use of biographical material between the 1940s and the mid 1970s (Bertaux 1981, p. 5). In the 1978 World Congress of the International Sociological Association in Uppsala, Bertaux arranged a separate session on life course methods that constituted a turning point, putting biographical methods squarely on the sociological map. A publication of the papers from the session has become a standard reference for biographical researchers (Bertaux 1981).

Debates early in the revival period were similar to those during the Appraisal Proceeding of The Polish Peasant. Can personal stories be relied upon? Are people telling the truth? How can reliability be checked against other sources of information? Are these really scientific data? However, wider questions about philosophy of science were also raised:

Biography resets in motion the Methodenstreit. It thus presents a unique opportunity for reopening a thorough debate on the subject of the logical, epistemological and methodological foundations of sociology; an occasion for the renewal of thought on the foundations of the social (Ferrarotti 1981, p. 21). 
The revival of biographical methods thus opened a debate about quantitative and qualitative approaches. The papers in the book edited by Bertaux (1981) make it clear that there are different approaches within biographical research, and that these are mainly related to the researchers' theoretical interests and research questions. Psychologists were mainly interested in the development of individual personality. Historians were interested in oral history and realistic accounts of the past (Hareven 1978; Thompson 1978, 1981). Empirical sociologists such as Bertaux, Elder and Denzin in their chapters in the 1981 book were oriented towards the study of social processes. Seen through their interpretation of the biographical method they considered it necessary to collect and assemble data and information of different types. However, none of the papers in the book addresses the topic of mixing methods explicitly.

Questions of ontology and epistemology dominated debates in biographical research in the 1990s (Nilsen 2008). Bertaux (1996) took part in the philosophy of science debates of the time; about realism versus 'idealism' or constructionism, positioning himself as realist and Fischer- Rosenthal and Rosenthal (1997) among others positioning themselves in the other camp. ${ }^{10}$ From a later vantage point, Miller (2000) sees this dichotomy as simplistic and instead makes a methodological distinction between realist, neo-positivist and narrative approaches. Bornat (2008) even more recently creates a further methodological classification; between the biographic-interpretive method, ${ }^{11}$ oral history, and narrative analysis. Others, inspired by Strauss and Glaser (1977), distinguished between case histories and case studies; the former focuses on the value of the single life story whereas the latter is concerned with setting the life story in social context (Plummer 2001). Following the same line of thinking, Roos (1997) discussed the realist-constructionist divide with reference to autobiographies and made the point that to have sociological merit contextual understanding is essential.

Drawing on the different viewpoints expressed in these writings we will now give a brief outline of what we consider to be the main characteristics of each biographical approach and their ontological/epistemological standpoints. We will make a distinction between a 'contextual approach' on the one hand and an 'interpretive approach' on the other. The origins of both approaches to current biographical research can be traced back to the Chicago School (Miller 2000, Plummer 2001, Roberts 2002).

\section{The contextual approach: lives in social contexts}

Studies that adopt this approach (Bertaux and Kohli 1984; Bertaux and Thompson 1997; Bertaux 2003) collect biographical material, mainly by interview, in order to study social change. Informants are usually selected on the basis of age and cohort. While the biographical material is centre stage, other types of data are also important since they provide the necessary context for the analysis of the qualitative material (e.g. Bertaux and Thompson 1997, Miller 2000, Roberts 2002). Inspired by Thomas and Znaniecki's study as well as the theoretical and methodological writings of Wright Mills (Bertaux 1981, Roberts 2002) the focus is on the relationship between wider social change and individual biography as we have discussed earlier in relation to the classic studies.

\footnotetext{
10 Biography\&Society Newsletter Dec. 1996, Dec. 1997.

${ }^{11}$ Fritz Schutze who was writing in Germany in the 1980s and who was greatly influenced by the Chicago School is usually credited with the development of the biographical interpretive method which was later to be refined by Fischer-Rosenthal and Rosenthal (1997) and much later in Britain by Tom Wengraf and Prue Chamberlayne.
} 
In contemporary studies within this tradition, methodological discussions rarely focus on the issue of the 'truth' of individual biographical accounts in the way that the early Chicago studies did. This is because their focus is not on single stories, but on the significance of the stories as a whole to understanding the wider social processes under scrutiny. This is not to say that this approach has a simplistic notion of truth and reality and takes stories at their face value. The point is rather that the knowledge sought is not only at the individual level (Bertaux 1997; Bertaux and Thompson 1997). The approach is realist in that it sees social reality as having consequences beyond individual beliefs. Individual accounts are interpretations, but they are interpretations set within a social context of factual events (Bertaux 1997; Roos 1997). The focus is therefore rarely only on the way the story is told; attention is as much on the features of the lives to which the stories testify (Nilsen 1996). Each story, or case, adds nuance to the totality, set within the different layers of social context within which the lives are lived. As Bertaux so succinctly puts it; 'behind the solo of the human voice one can hear the music of society and culture' (Bertaux 1990, p. 168). The epistemological standpoint implies that there is reality beyond language and discourse but that reality must be studied in context; in relation to time and space.

\section{The interpretive approach: narratives and texts}

Denzin was a key figure in developments of the 'narrative turn'. A student of Blumer, his early studies were influenced by symbolic interactionism; towards the end of the 1980s his focus shifted to what he termed 'interpretive interactionism' in which discourses and narratives - 'stories' - became his main interest.

Ethnographies, biographies, and autobiographies rest on stories which are fictional, narrative accounts of how something happened. Stories are fictions. A fiction is something made up or fashioned out of real and imagined events. History, in this sense, is fiction. A story has a beginning, a middle, and an end. Stories take the form of texts, They can be transcribed, written down, and studied. They are narratives with a plot and a story line that exists independent of the life of the storyteller or narrator. Every narrative contains a reason or set of justifications for its telling (Denzin 1989, p. 41).

A paradox of the interpretive tradition is that it rests upon the same kind of questions which 'the positivists' had posed about biographical accounts during the Appraisal Proceedings referred to earlier. Are they truthful? Can they be relied upon? Both positivists and constructionists argue that biographies are not truths. However, whilst an extreme positivist approach would not contest the idea of a reality that can be captured by the 'right' type of data and methods, an extreme interpretive perspective would involve questioning whether there is such a thing as reality beyond language - i.e. knowledge about reality expressed in language is the only reality that exists. From these widely different standpoints on questions of philosophy of knowledge, interpretevists and positivists draw very different, yet similar, conclusions about biographical material: where positivists dismiss these data altogether because they are not 'objective' enough, the constructionists see them as parallel to works of fiction that can be analysed with the same techniques as literary texts. In either case they are rendered questionable as far as truth is concerned.

The interpretive approach pays more attention to single stories than the contextual approach. Plummer, a key exponent of biographical research in the interpretive tradition, makes the following point about why biographical studies are of interest: 
[...] and what lies at the heart of this enormous outpouring of writing about 'the modern human being' is the idea that a highly individuated, self-conscious and unstable identity is replacing the old, stable, unitary self of traditional communities. The new selves are 'constructed' through shifts and changes in the modern world, and partly create a new sense of permanent identity crisis. The search for 'understanding' and making sense of the self has become a key feature of the modern world.' (Plummer 2001, p. 83)

The focus of attention in this analysis is 'inward', on individual narratives rather than 'outward' towards the wider social context to which the person belongs. This is not to say that social phenomena beyond the individual are of no interest. They are, but the terminology used to refer to society is different from that of a contextual approach. Language and discourse have a key place in the interpretive approach. For example, history is referred to as epochs rather than specific periods; concepts of 'modernity', late modernity' and 'post modernity' abound (Plummer 2001).

Notions of context vary between the two approaches; structural dimensions have different meanings. In the contextual approach age for instance refers both to individual experience and interpretation, as well as to age as a structuring element relating to social institutions (Giele and Elder 1998; Riley 1987). From an interpretive perspective Plummer (2001) points to the importance of including more than chronological age in interpretations of biographical material; "subjective age (how old the person feels), interpersonal age (how old others think you are) and social age (the age roles you play - so you can 'act much younger - or older than your age"" (Plummer 2001, p. 129). All are considered equally important. These ways of addressing age demonstrate that the research questions addressed from the two epistemological standpoints may vary considerably.

\section{Three ways of mixing methods in current studies using biographical methods}

In the final section of this chapter we will discuss ways in which methods are, and can be, mixed in biographical research. We will distinguish between three different ways of integrating data and methods. As we have demonstrated thus far, much of the research that employs the range of biographical methods in the analysis phase integrates inferences made on the basis of different types of data but often in implicit ways. The mixed methods research literature of the recent decade and a half has been influential in making researchers think about the ways in which they can integrate different methods and types of data more explicitly. Greene et al (1989, p. 127) was among the first to define ways of integrating data from different methods in mixed methods research designs. They set out a five fold classifications; triangulation where convergence of results is sought arrived at by different methods; complementarity which seeks elaboration, enhancement and clarification of results from one method with results from another; development which is to use the results of one method to develop or inform another method; initiation which seeks to interrogate results from one method with questions or results from another method; expansion seeks to extend the breadth and range of enquiry by using different methods for different enquiry components.

Much of the mixed methods research literature refers to studies in which weight is given to both qualitative and quantitative data, albeit in varying proportions (see Cresswell et al 2003 for an overview). However, as Brannen $(1992,2004)$ and others (Tashakorri and Teddlie 1998) have argued, it is more complex than this; qualitative and quantitative elements may be 
introduced into different phases of the research process: not only the research design phase but also the fieldwork phase and the phases of interpretation and contextualisation. These phases can be distinguished in relation to: (a) the context of enquiry in which methods are chosen to address substantive and theoretical questions; and (b) the context of justification in which data are discussed in relation to the methods, assumptions and theories by which they are constituted (Kaplan 1964).

Some researchers who employ biographical approaches, especially those working within a qualitative interpretive tradition, do not collect more than one type of primary data and therefore do not focus their attention on the methodological aspects of this fact in their data analysis (e.g. see Wengraf 2001). In some studies where both quantitative and qualitative data are collected, researchers have tended to make the qualitative data invisible in the analysis, suggesting a lack of systematic integration (Elder 1999). Some biographical researchers link qualitative studies to existing data sets such as cohort studies or archived data- what we term linked designs. Rarely are contemporary cohort studies or longitudinal studies designed with a qualitative study in view, although, in the UK at least, with the increasing cost of collecting new data, more linked designs to such studies are expected to take place.

Researchers who carry out cross national studies, involving several countries, increasingly use methods and data for the theoretical purpose of addressing a number of layers of social context (micro, meso and macro); such an approach underlines the relation between agency and structure and the importance of addressing this methodologically (Layder 1998: 14). These contextual layers require the integration of the respective data in the analysis phase. Analysis here therefore typically involves working across different methods.

Among researchers working in interpretive traditions the approach to integration tends to be quite different. For example, those espousing the biographic- interpretive method (Wengraf 2001) integrate different types of data within methods as we shall describe below. These three ways of mixing methods in biographical studies are now considered. However they represent only some among a number of possibilities.

\section{Linked quantitative and qualitative designs}

Many examples in this category come from the disciplinary intersection between history and sociology. Hareven's historical study of the relationship between work and family in an industrial community in the USA (Hareven 1982) was one of the earliest to address explicitly issues of combining different data. The material she integrated in her study were "company files and employees' files from Amoskeag, vital records, parish records, insurance records, and linkage with the 1900 census" (Hareven 1982, pp 385-386). This massive material was combined with individual interviews. On the differences between surveys and interviews, Hareven observed: 'Like surveys, it [a life history] recalls attitudes and perceptions, but, unlike surveys, it places these perceptions in the context of an individual's life history. These perceptions are exceptionally valuable not as individual case histories but as historical, cultural testimonies.' (p. 382). Although she did not set out to do a mixed methods research design, she nevertheless integrated both quantitative and qualitative material in the study, and also discussed their methodological implications:

Whereas the quantitative analysis provides structural evidence concerning the organisation and behaviour of kin, the oral-history interviews offer insight into the nature of relationships and their significance to the participants. The empirical analysis 
reported here - although attempting to weld both types of evidence - at times presents two different levels of historical reality, each derived from a distinct type of data ( $\mathrm{p}$. $371)$.

Throughout the book all the types of data are integrated and discussed to explore and explain different layers of contexts of the research questions. This makes Hareven's study one of the first 'biographical' studies where data and methods of analysis are fully integrated and the merits of each type of data, together and separately, are explicitly addressed.

Another example where mixed methods have been made an explicit issue of concern is Laub and Sampson's (1998) use of the Gluecks' longitudinal data. They successfully integrated the original quantitative and qualitative data in the analysis and interpretation and continued to do so as they followed up the original sample (Laub and Sampson 1993). Laub and Sampson (1998) describe 'merg(ing) quantitative and qualitative data to provide a more complex portrait of criminal offending over the life course' (p. 221) by combining variable based analysis with data on persons. Their strategy was to select a random subset of cases for intensive qualitative analysis that were consistent with the quantitative data analysis and to explore consistencies and inconsistencies between these according to the different lenses that each data set and method offered. They argue that the approach had two methodological benefits. First, it resulted in the enhancement of quantitative data through recourse to the qualitative life histories which demonstrated the complex processes underlying the persistence of and desistence from crime. Second, by examining residual or 'negative cases' that did not fit the quantitative results, it led the researchers to examine 'unidentified pathways into and out of crime' (p.222).

Laub and Sampson (1998) report some additional misgivings about the original data collected by the Gluecks which point to the nature of biographical research and the ways in which the research design of this large scale longitudinal study failed to address the concern with understanding changes in human lives. In particular they note the Gluecks' failure to explore turning points in the life course. Thus they decided that it was important in their own follow up of the Gluecks' sample to adopt a life history approach in their interviews that enabled respondents to reflect retrospectively upon the turning points in their life course. They argue that 'without qualitative data, discussions of continuity often mask complex and rich qualitative processes' (Sampson and Laub 1997 quoted in Laub and Sampson 1998, p. 229). Moreover, like Hareven, they also make the crucial claim for the biographical approach; that the data provide an opportunity for their interpretation in relation to the historical context in which the respondents are studied, in the case of crime the type and level of crime that were prevalent at the time.

As noted above, Paul Thompson and Daniel Bertaux have advocated the integration of qualitative and quantitative data (Bertaux and Thompson 1997). Thompson (2004) notes that one of the key advantages provided by existing large scale studies is the provision of systematic samples from which to select participants for qualitative study. He gives an account of his attempts to link a qualitative study carried out in the 1990s of growing up in step families to a birth cohort study, the National Child Development Study whose participants were born in 1958. Thompson and colleagues secured a sample of 50 men and women with whom to carry out life story interviews (Gorell Barnes et al 1997). They specified the criterion that selected respondents from the cohort study should have become step family members between the ages of 7 and 16. Thompson notes that the respondents " had never, over 30 years, been given the chance to tell their own life stories' (Thompson 2004 
p. 249) but that most valued the opportunity to do so. Moreover Thompson also notes that participation in life stories increased their cooperation in the next wave of the cohort study, a fact which he found reassuring given the reluctance he encountered among some 'guardians' of these large scale data sets to allow access to other research terms, usually on the grounds that this would jeopardise future response rates.

Significantly Thompson and colleagues found that 10 out of the 50 sample members had been classified in the contemporaneous cohort data differently compared with their retrospective life story interview accounts; most had been step family members well before the age of 7 (Gorell Barnes et al 1997). In order to delve into the reasons for these discrepancies the research team sought access to the original paper questionnaires but found they no longer existed. Thompson reflects on the importance of the historical context and of the significance of time perspectives upon differences between retrospective and contemporaneous biographical data. He also considers who was missing from the quantitative study in terms of the selective effects of taking part in a longitudinal study. He suggests that this latter factor had particular relevance for the research focus on step families. 'Could it be that in order to maintain membership of a longitudinal study... you have to have a stable and coherent life?'(Thompson 2004 p. 251). If this is so then this reinforces the case for qualitative studies to be linked to national cohorts and longitudinal quantitative studies; both in terms of using these as sampling frames but also as a strategy to interrogate these samples by targeting non participants and those who are likely to drop out of such long term studies.

In the studies by Laub and Sampson (1998), as well as in Gorell Barnes et al (1997), qualitative and quantitative biographical data were linked in a mixed method design. Yet both these examples were studies that were conducted by different teams, at different times and for different purposes. The benefits of the linkage included the opportunity to pose new critical and theoretically interesting questions to the existing quantitative longitudinal data - the strategy of initiation as defined by Greene et al (1989); to ask, for example, under what research conditions and historical/ life course moments are certain life events such as becoming a step family likely to be reported or not reported? A second benefit is that of 'completing the picture'; by using retrospective biographical interviews to allow respondents to interpret their own lives - the integration strategy of complementarity.

\section{Integration across methods}

Particular kinds of research demand multiple data sources. Cross national research, especially multi-country studies, are a case in point and involve highly explicit research designs ${ }^{12}$. These typically require researchers to bring into the frame wider policy contexts, existing national and international social trend data, and data about individuals in local and family contexts. Methodological texts give surprisingly little attention to this issue. Indeed only when the issue of working across different countries is addressed does contextualisation come to be seen as a matter deserving special attention (Hantrais1999).

A research design for a seven country cross national study in which we were both involved used biographical methods, among a range of other methods. Carried out in 2002-05 (Lewis, Brannen, Nilsen 2009 in press) it sought to examine the experiences of working mothers and fathers who had young children from their own perspectives and to make sense of their lives

\footnotetext{
${ }^{12}$ In EU funded Framework Programme research, every stage of the research process is broken down into what are known as work packages in which different teams take on responsibilities for leading on and carrying out particular tasks.
} 
in relation to a number of layers of social context: public policies, global economic forces, the workplaces of parents and their families and communities. The design involved mapping and analyzing public policies and social and economic trend data; carrying out case studies of the organizations in which parents were employed (in a finance company and a social services department in each country); and employing focus groups and biographical interview methods with parents. A variety of data was collected about parents' workplaces including documentary data, and interviews with managers at different levels were conducted.

The project's design is an example of an embedded case study in which different methods and types of data were integrated. The countries, workplaces and parents were selected from larger (linked) wholes (Yin 2003) while clear theoretical rationales were given for the choice of cases at all the contextual levels and in the different phases of the research process; for cases must be "cases of something' (Brannen, Nilsen and Lewis 2009 in press, Nilsen and Brannen 2005). The countries and organisations were selected on the basis of principles of both similarity and difference.

The benefits of adopting this design in relation to the different contextual layers became evident in the analysis of the interview and focus group data with parents. In making sense of the material based on the primary data especially that written up by the other national teams we found that the wider context was often missing (Nilsen and Brannen 2005). To facilitate interpretation, each national team was paired and exchanged drafts of national reports of the organisational case studies and the individual parent case studies that had been written in English. Each team was asked to report back on these in relation to particular research questions. This meant that the corresponding team had to supply the missing context to help the other team make sense of the data. The eyes of those who stand outside a society are indeed helpful in making manifest what an insider takes as given.

\section{Integration within methods}

The biographic-interpretive method is an example of a method in which the contextual and interpretive data are integrated within a single research method (the interview) and are separated in the analysis (Wengraf, 2001). The contextual and interpretive data are then brought together again in the final interpretation. Like for instance the approaches of Kohli (1981), Nilsen (1996) and others to biographical material, the biographic-interpretive method is therefore sensitive both to the 'told story' (the biographical account) and the chronology of the life course and the historical context of the 'lived life' (life histories). The method is justified however less in terms of providing contextual understanding for the interpretations that informants themselves provide on their lives. Instead the rationale is about increasing the explanatory potential of the study by ruling out competing hypotheses and explanations for the individual's life trajectory and the agency of the individual in directing it. This is done through setting up a panel the members of which engage in a close sequential analysis both of the life course sequence and 'facts' of the person's life and the unfolding textual account of the 'life story'. 13

Brannen and colleagues employed the biographic-interpretive interview with some adaptations in their study of four generation families, which examined the ways in which work and care were interwoven in the lives of families and their members across the

\footnotetext{
${ }^{13}$ Counter hypothesising is crucial for enabling the researcher to move beyond their own intuition and common sense and thereby expand the sociological imagination (Wengraf $2001 \mathrm{p} 258$ ).
} 
generations (Brannen, Moss and Mooney 2004). They interviewed between 8 and 5 members of 12 families (71 individuals); parents of a young child (under 7); grandparents; and great grandparents ${ }^{14}$. Quoting Thompson (1977) from the study The Edwardians, they argued that it was important to look closely at the actions and meanings of individuals that underpinned the grander picture which historians and sociologists created from statistical sources and the documentation of 'facts'. The full biographic-interpretive method of analysis was not adopted in this study. In analytically distinguishing life course phases and historical change, they found that few research participants referred to the external historical context, that is, they did not stray from the boundaries of their own family and personal lives. Their interpretive accounts moreover reflected contemporary normative discourses rather than those of the times in which their life events had occurred. To recreate the historical context, historical knowledge about the relevant periods (the interwar and immediate postwar period in particular) was brought to bear in the analysis of each interview through the use of historical time lines; this process was also facilitated by the fact that two members of the team were historians by disciplinary origin. Making the links between biography, family generations and historical time was highly demanding encompassing as it did the lives of families across the $20^{\text {th }}$ century.

Another example of 'integration within methods' is one particular phase of a study in which interviews were combined with life lines. Life lines are graphs where important factual events and phases in an informant's life course are portrayed chronologically in relation to age and historical time. In some studies such life lines are created with the interviewees after the interview, in other instances the information is derived from the interview and graphs are drawn by the researcher at a later point (Nilsen 1994). In the cross national study (Brannen, Lewis, Nilsen 2009 in press) that we earlier referred to as an example of 'integration across methods' life lines based on the biographical material were also used. They were a valuable resource in comparing cases and contexts cross nationally. Teams discussed individual life lines relating to the participating countries. In order to elicit similarities and differences and the reasons for these it was necessary to draw out the relevant national historical contexts and their institutional specificities in relation to the life course phases and turning points of the interviewees. Researchers native to a country thus came to realise that much of their knowledge about their own national context was taken for granted and implicit; the occasion for interpreting life lines with colleagues without such insider understanding served to make explicit the layers of context which were relevant to understanding the lives of the interviewees (Nilsen and Brannen 2005). This is an example of a study in which 'integration within methods' took place at a particular phase while as a whole the study can be categorised as an example of 'integration across methods'.

\section{In conclusion}

\footnotetext{
${ }^{14}$ Interviews were in three parts. In the first part, interviewees were invited to give an account of their lives, with a minimum of guidance and intervention from the interviewer. Encouraged to begin their story where they chose and to use their own words, the interviewees were provided with an opportunity to present their own gestalt (Wengraf 2001). Some gave stories which lasted over an hour with no break; others' narratives lasted minutes. In the second part of the interview, the interviewer invited the respondent to elaborate the initial narrative in relation to salient events or experiences that had figured in it. ${ }^{14}$ Finally, using a more traditional semi-structured style of interview, the interviewer asked additional questions relating to the specific foci of the study. Depending upon interviewees' responses in the first two parts, this could be lengthy or short.
} 
In this chapter we have described key developments in and different varieties of biographical research with particular reference to sociology. We have demonstrated that the practice of mixing methods in this type of research has a long history. However, biographical studies have placed emphasis to different degrees upon the use of more than one method and data source. Moreover, even those who have used more than one source of data or method have rarely been explicit about issues of method mixing and data integration; they have only recently begun to consider how different methods can contribute to the processes of analysis and interpretation. In some respects this story is very much the same as for other combinations of methods. Indeed the creation of a clear methodological field of mixed methods research is a recent development that has occurred over the last 15 years.

We began the chapter with a discussion about The Polish Peasant in Europe and America, and the study's use of 'human documents' (interviews, letters, diaries, public records and so on). Such practices raised concern at that time because they challenged the very notions of what data and methods in sociology should constitute. In the period between 1930 and 1970 biographical material was largely collected in quantifiable form and based on large samples through the use of surveys and public records. Interviews were regarded as background information only; they were not considered 'scientific' (reliable) enough and thus were used for insights and illustrative purposes despite the systematic basis on which they were often collected. In the late 1970s there was a revival of biographical methods within sociology. From that time a whole range of approaches and methods has developed within biographical research. A few approaches have explicitly addressed the issue of mixing methods and integrating different types of data. Others have continued to adopt the more traditional strategy of prioritising one primary data source and using the research literature and knowledge of the wider context in implicit and often selective or random ways.

As for the future, biographical research (and qualitative research in general) are likely to remain popular in stable societies like the UK and Norway (our own countries) because of the importance placed by government on self regulating citizens and a concern with subjectivities (Alasuutari, Brannen and Bickman 2008). It will also continue to be of relevance in societies undergoing rapid change (see the European Sociological Association Network on biographical research). There are a number of developments that lead us to suppose that biographical methods will be an important part of social science research methods in the future not only as a solo method but as an important part of a mixed method research strategy. The methods of biographical research are likely to have a particular appeal within the growing field of participatory research which, as the Handbook testifies, is an important stimulus for mixed method research (the chapter by Mertens in the Handbook). Another trend suggestive of their increasing importance is the growth in social science training in hyper media technologies. Yet another is the rising cost of collecting new data and the constraints of ethics committees and procedures. These constraints will mean that new researchers may need to draw upon data archives for their material. As archived material grows and becomes more available and as 'e-social science' makes data linkage easier, so the value of biographical material is likely to rise especially when it can be used in combination with other existing data sources. Lastly, as more research funding is devoted to birth cohort studies and very large scale household panel studies ${ }^{15}$, so the demand for more nuanced forms of explanation will grow. We may indeed see a return to the ambitious aims of some of the classic biographical

\footnotetext{
${ }^{15}$ In the UK, the Economic and Social Research Council has recently launched a new national household Panel study of 40,000 households and is proposing to set up a further national birth cohort. In Norway and other Scandinavian countries it is possible for researchers who have permission to link longitudinal information on individuals from a number of public records.
} 
studies namely to link qualitative methods to quantitative longitudinal and cohort studies. If such developments take place, and the issues of making explicit the ways of mixing methods and integrating different types of data are addressed, this would indeed constitute significant methodological progress.

\section{References}

Alasuutari, A, Brannen, J and Bickman, L (2008) Introduction in Alasuutari, P, Brannen, J and Bickman, L (2008) (eds) Handbook of Social Research, London: Sage

Blumer H. 1954 What is Wrong with Social Theory? in American Sociological Review 19, pp. 3-10

Blumer, H 1979. Critiques of Research in the Social Sciences. An Appraisal of Thomas and Znaniecki's The Polish Peasant in Europe and America. New Brunswick: Transaction Books

Bertaux, D (ed) 1981 Biography and Society. The Life History Approach in the Social Sciences. London: Sage

Bertaux D 1990 Oral History Approaches to an International Social Movement in E. Øyen (ed) Comparative Methodology London: sage

Bertaux, D. 1996 A Response to Thierry Kochuyt's 'Biographical and Empiricist Illustions: A Reply to Recent Criticisms' in Biography and Society Newsletter, December 1996, pp. 2-6

Bertaux D. 2003 On the Usefulness of Life Stories for a Realist and Meaningful Sociology in R. Humphrey, R. Miller, E. Zdravomyslova (eds) Biographical Research in Eastern Europe. Altered lives and broken biographies. Aldershot: Ashgate,

Bertaux, D and M Kohli 1984. The Life History Approach: A Continental View. In Annual Review of Sociology, 10, pp. 215-37

Bertaux D and P Thompson 1997. Introduction in D. Bertaux and P. Thompson (eds) Pathways to social class: a qualitative approach to social mobility. Oxford: Clarendon Press.

Bornat J (2008) Biographical methods in Alasuutari, P, Brannen, J and Bickman, L (2008) (eds) Handbook of Social Research, London: Sage

Brannen, J. (1992). Mixing Methods: Qualitative and Quantitative Research. Aldershop: Ashgate Publishing Limited.

Brannen, J. (2004). Working qualitatively and quantitatively. In C. Seale, G. Gobo, J.F. Gubrium, \& D. Silverman (eds.), Qualitative Research Practice. London: Sage.

Brannen, J, Moss, P and Mooney A (2004) Working and Caring over the Twentieth century: Change and continuity in four-generation families ESRC Future of Work Series, Basingstoke: Palgrave Macmillan 
Brannen, J. (2005). Mixing methods: The entry of qualitative and quantitative approaches into the research process. The International Journal of Social Research Methodology, Special Issue, 8(3), 173-185.

Brannen, J, A. Nilsen and S. Lewis (2009) Research Design and Methods: doing comparative cross-national research in Lewis, S Brannen J and Nilsen A (2009 in press) (eds) Work, Family and Organisations in Transition: A European Perspective Bristol: Policy Press

Cresswell, J.W. (2003). Research Design: Qualitative, Quantitative and Mixed Method Approaches. Thousand Oaks, CA: Sage.

Denzin, N 1989. Interpretive Biography. Qualitative Research Methods Series 17. London: Sage

Elder G. 1999 [1974] Children of the Great Depression. Social Change in Life Experience. Oxford: Westview Press

Elliott, J 2005 Using narrative in social research: qualitative and quantitative approaches, London: Sage

Ertzberger C and Kelle U (2003) Making inferences in mixed methods: the rules of integration. In Tashakorri and C Teddlie (eds) Handbook of Mixed Methods in Social and Behavioural research, Thousand Oaks CA: Sage

Ferrarotti, F 1981. On the Autonomy of the Biographical Method in Bertaux, D (ed) 1981 Biography and Society. The Life History Approach in the Social Sciences. London: Sage

Fischer-Rosenthal W and G. Rosenthal 1997 Daniel Bertaux's Complaint or Against False Dichotomies in Biographical Research in Biography and Society Newsletter, December 1997, pp. 5-11

Giele. J and G. Elder 1998 Life Course Research: Development of a Field. in Giele and Elder (eds) Methods of Life Course Research. Qualitative and Quantitative Approaches. London: Sage

Glaser, B and A Strauss 1967. The Discovery of Grounded Theory: Strategies for Qualitative Research Chicago: Aldine

Glueck, S and E. Glueck 1930. 500 Criminal Careers New York: Alfred A Knopf

Glueck, S and E. Glueck 1943. Criminal Careers in Retrospect New York: The Commonwealth Fund

Glueck, S and E. Glueck 1950. Unravelling Juvenile Delinquency. New York: The Commonwealth Fund

Gorell Barnes, G, Thompson, P, Daniel, G and Burchardt N (1997) Growing up in stepfamilies, Oxford: Oxford University Press 
Greene, J., Caracelli, V.J., \& Graham, W.F. (1989). Towards a conceptual framework for mixed-method evaluation designs. Education, Evaluation and Policy Analysis, 11(3), 255-274.

Hantrais L 1999 Contextualisation in cross national comparative research International Journal of Social Research Methodology, 2, 93-108

Hareven, T 1978 Introduction: The Historical Study of the Life Course in T. Hareven (ed) Transitons. The Family and the Life Course in Historical Perspective New York: Academic Press

Hareven T.1982 Family Time and Industrial Time. The relationship between the family and work in a New England industrial community. Cambridge: Cambridge University Press

Kaplan, A 1964 The conduct of enquiry: Methodology for behavioural science San Francisco: Chandler

Kohli, M 1981 Biography: Account, Text, Method in D. Bertaux (ed) Biography and Society. The Life History Approach in the Social Sciences. London: Sage

Laub J and Sampson R (1998) Integrating quantitative and qualitative data in J Giele and G Elder 1998 Methods of life course research Thousand Oaks: Sage

Laub and Sampson 1993 Turning points in the life course: why change matters tot eh study of crime Criminology 31 301-325

Layder D 1998 Sociological practice: Linking theory and social research London: Sage

Lewis D. and R. Smith 1980. American sociology and pragmatism : Mead, Chicago sociology and symbolic interaction Chicago: University of Chicago Press

Lewis, S Brannen J and Nilsen A (2009 in press) (eds) Work, Family and Organisations in Transition: A European Perspective Bristol: Policy Press

Mertens, D (2003) Mixed methods and the politics of social research: the transformativeemancipatory perspective in A Tashakorri and C Teddlie Handbook of Mixed Methods in Social and Behavioural Research. London: Sage.

Miller R. L 2000. Researching Life Stories and Family Histories London: Sage

Mills , C. Wright 1939 Language, Logic and Culture in American Sociological Review vol. IV no. 5 pp. $670-680$

Mills. C. Wright 1940a Methodological Consequences of the Sociology of Knowledge in American Journal of Sociology vol XLVI no n3, pp. 316-330

Mills. C. Wright 1940b Situation Actions and Vocabularies of Motive in American Sociological Review vol V no 6 904-913 
Mills , C. Wright 1963 [1954] IBM Plus Reality Plus Humanism=Sociology in I. L Horowitz (ed) Power, Politics and People. The Collected Essays of C. Wright Mills Oxford: Oxford University Press

Mills , C. Wright 1966. Sociology and pragmatism : the higher learning in America. New York: Oxford University Press

Mills, C. Wright 1980 [1959]. The Sociological Imagination London: Penguin Books

Nilsen A 1994. Life Lines - A Methodological Approach in Bjerren, G and I. ElgqvistSaltzman (eds) Gender and Education in a Life Perspective: lessons from Scandinavia. Avebury: Ashgate

Nilsen A 1996 Stories of Life - Stories of Living: Women's Narratives and Feminist Biography in NORA, Nordic Journal of Women's Studies no. 1 vol 4 pp. 16-30

Nilsen, A 2008. From Questions of Methods to Epistemological Issues: The Case of Biographical Research in Alasuutari, P, Brannen, J and Bickman, L (2008) (eds) Handbook of Social Research, London: Sage

Nilsen, A and J. Brannen 2005. Interview Study Consolidated Report. Research Report \# 8 RIHSC: Research Institute for Health and Social Change

Platt, J 1996. A History of Sociological Research Methods in America. 1920-1960. Cambridge: Cambridge University Press

Plummer, K 2001. Documents of Life 2. An invitation to a critical humanism. London: Sage

Riley, M 1987. On the significance of age in sociology in M. Riley, B. Huber, B. Hess (eds) Social Structures and Human Lives London: Sage

Roberts, B. 2002 Biographical Research Buckingham: Open University Press

Roos, J. P. 1997. Context, Authenticity, Referentiality, Reflexivity: Back to Basics in Autobiography in V. Voronov \& E. Zdravomyslova (eds) Biographical Perspectives on Postsocialist Societies. St. Petersburg: Center for Independent Research

Ryder N 1965 The cohort as a concept of social change in American Sociological Review 30 843-861

Sampson R and Laub J 1997 Crime in the making: pathways and turning points through life Cambridge MA: Harvard University Press

Strauss, A and B. Glaser 1977. Anguish. A Case History of a Dying Trajectory. Oxford: Martin Robertson

Tashakorri A and Teddlie 1998 Introduction to mixed method and mixed model studies in the social and behavioural sciences In Mixed methodology: combining qualitative and quantitative methods Thousand Oaks, CA: Sage p3-13 
Thomas, W.I and F. Znaniecki 1958 [1918-1920] The Polish Peasant in Europe and America, vol 1-2. New York: Dover Publications

Thompson P. 1978 The Voice of the Past. Oral History. Oxford: Oxford University Press

Thompson. P 1981. Life Histories and the Analysis of Social Change in Bertaux, D (ed) 1981

Biography and Society. The Life History Approach in the Social Sciences. London: Sage

Thompson, P. (2004). Researching family and social mobility with two eyes: Some experiences of the interaction between qualitative and quantitative data. The International Journal of Social Research Methodology, 7(3), 237-259.

Wengraf, T 2001 Qualitative research interviewing London: Sage

Yin, R.K. (2003). Case Study Research. Design and Methods. $3^{\text {rd }}$ edition. London: Sage

Znaniecki, F. 1934. The Method of Sociology. New York: Farrar and Rinehart 